scars as if they were campaign medals. What will the next status symbol be?-I am, etc.,

Romford

LÉON M. SHIRLAW

\section{Cerebrovascular Accident}

SIR,-Who started this misnomer? In popular terminology this can only denote trauma and as such would be properly referable to H.M. Coroner in the case of death. If we need a term to include thrombosis, haemorrhage, and embolism would it not be better to call this an "event," an "incident," or in present terms a "happening?" We know from the old days of maternity the description "accidental haemorrhage" but this very rarely occurs nowadays. The use of the word "accident" causes wonderment, disbelief, and grief to the relatives involved. Please may we use the word "event?"-I am, etc.

Frederick M. M. Eyton-Jones

Brighton

\section{A Kidney Sling}

SIR,-In order to operate on the kidney substance, the pelvis, or the renal pedicle in performing, for example, a partial nephrectomy, pyelolithotomy, or renal denervation it is necessary to support the kidney in the appropriate position. One method of doing so is to pass linen tape around both poles of the kidney and clip the ends in a haemostat, which the assistant then holds. The kidney sling accomplishes this object somewhat more conveniently and efficiently. It consists of two metal ellipses, one swivelled inside the other at a joint eccentrically placed. A fine chain by which the sling is suspended is looped through the ellipses (Fig. 1).

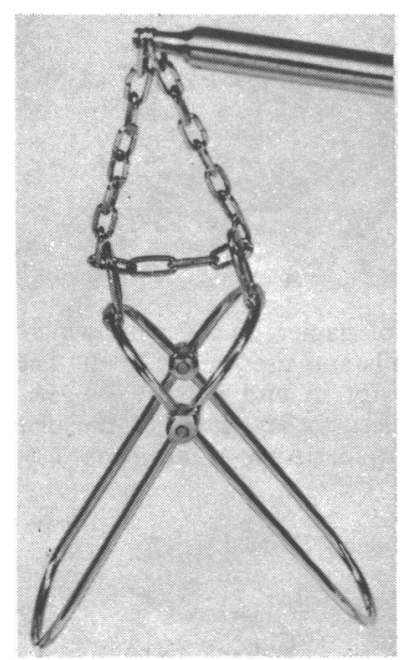

In use, one of the ellipses of the sling is placed under each of the renal poles after the kidney has been mobilized. The suspensory chain attached to a supporting tommy bar is then hung from the chuck of a "mechanical assistant" (Tinckler. In press), which is then adjusted to support the kidney in the required position or alter natively held by the hand of the surgical assistant. A subsidiary action of the suspensory chain is gently to approximate the ellipses, thus preventing them from slipping out of position (Fig. 2).

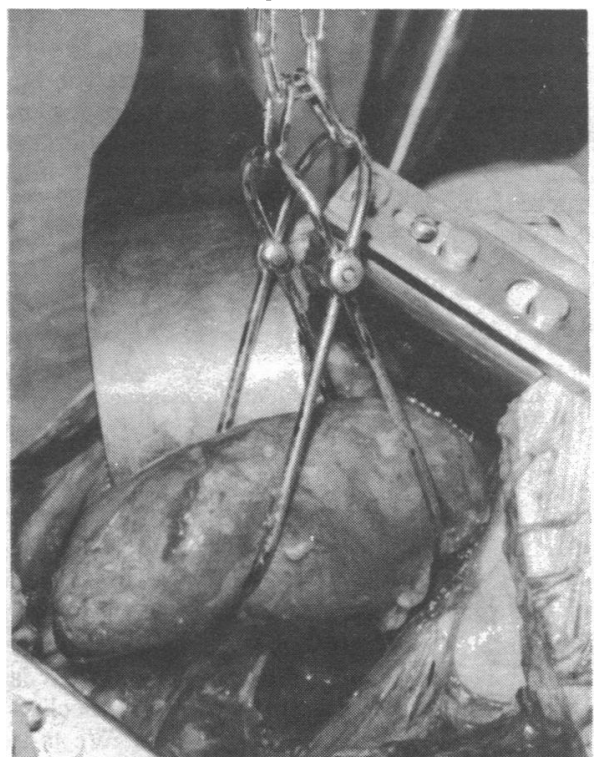

I wish to acknowledge the help I have received from Mr. R. Pickering in the development of this instrument, which is available from Down Bros., Mayer and Phelps, Ltd., Church Path, Mitcham, Surrey.-I am, etc.,

\section{F. TINCKIER}

Maelor General Hospital Wrexham

\section{Eosinophils in the Blood Film}

SIR,-Can anyone explain why eosinophil cells in the peripheral blood film often occur in groups of two or three or more, separated by perhaps one m:croscope field width? It is a fact easily verified that if one notes an eosinophil in a blood film and searches around it to a radius of one or two fields, rather than continuing in a straight line, very often one will find another cell of the same type, often a basophil too. In this way it is easily possible to increase the figures for eosinophils and basophils in the differential blood count, perhaps by several percentage points.

Possibly this is a surface effect only, as has been suggested. Or the red cells, being of uniform size, tend to form a regular lattice; the rather heavily granulated cells of both types, and also the monocytes, then tend to act as impurities do in the classic experiment of the "bubble raft" and to congregate in the faults of a two dimensional lattice. Alternatively, even in the blood stream, cells of the same kind might tend to travel together.

It is an obvious source of inaccuracy in doing the standard differential white blood count on one or two hundred cells. Where there is an eosinophilia the effect is fortunately less evident.-I am, etc.,

W. T. MEnKR

King's College,

Carnbridge

Some Problems of Acute Osteomyelitis

SIR,-Your recent leading article (11 November, p. 317) on problems in acute osteomyelitis contained much sensible comment. However, there is one point on which cannot agree, and I am sure that I speak also for many of my colleagues. Both in your own journal and in others it is becoming increasingly common to hear that it is no longer necessary to drill the metaphysis as part of the management of acute osteomyelitis, and may be harmful to do so. It is also said that this is now the view of the majority of orthopaedic surgeons.

Thus baldly stated, such comment is misleading and, in its possible influence on the education of orthopaedic trainees, harmful. I would be interested to know of the source from which such a statement can be made with such apparent authority. Your leader quotes failure rates of between $10 \%$ and $15 \%$ in the suggested management of acute osteomyelitis, and one can but wonder whether there might not be some relationship between the two comments.

In our practice it is accepted that where acute osteomyelitis can be diagnosed within the first 24 hours from onset and treated immediately with correct antibiotics, then it may be satisfactorily controlled. It is not often that acute cases are referred so promptly. It is also accepted that where a subperiosteal collection of pus has already been allowed to form, then the damage is done and further surgery is unlikely to influence the outcome. But in circumstances where an acute episode is not being properly controlled by antibiotics and the child is in pain and toxic, then this stage in the clinical picture seems to be associated with the formation of an abscess actually within the marrow cavity. If allowed to continue, the raised intraossesous pressure will cause death of surrounding bone, and its subsequent perforation will give rise to a subperiosteal abscess and a high chance of later chronicity. This process can be abruptly and successfully terminated by timely and judicious drilling of the metaphysis (whether or not the procedure is accompanied by the traditional resulting jet of pus). Although a subperiosteal collection may on occasion result, the death of bone is prevented. Antibiotics can then pervade the whole of the affected area and the clinical condition improves dramatically.

There is still a very important place for properly timed surgical intervention in the treatment of acute osteomyelitis. That this view exists should not be lost upon future generations of orthopaedic surgeons.-I am, etc.,

St. Thomas's Hospital

D. A. ReYNolds London S.E.1

\section{Conscientious Objection to Abortion}

SIR,-Could I add to the refreshing letters of Mr. R. L. Walley, (28 October, p. 234) and Dr. Margaret B. Wilkinson (18 November, p. 430)?

It is not just as a gynaecologist that an objection to abortion can get you into trouble. As a general practitioner, of course, your decision is just as vital as if you were wielding the curette yourself; in fact more so. For a time, I used to argue that a patient whose G.P. advised her against abortion had a right to a second opinion and to be referred to a gynaecologist, who narurally had much less information on which to form an opinion. He therefore must accept the patient's request or declare his basic objection. The G.P. has passed the buck.

"Conscientious objection" in this context 